\title{
Histologia fácil: atlas histológico para dispositivos móveis ${ }^{1}$
}

\author{
Helder Camilo da Silva Pereira ${ }^{2}$, Lucas Rannier Ribeiro Antonino Carvalho ${ }^{3}$, Márcia Verônica Costa \\ Miranda $^{4}$, Ricardo Romão Guerra ${ }^{3}$
}

\begin{abstract}
Resumo: É inegável a evolução dos meios de comunicações e sua utilização em todas as áreas de ensino e pesquisa. Hoje, telefones possuem infinitos recursos que atendem às variadas demandas do cotidiano de seus usuários. A rotina acadêmica incorporou a tecnologia dos smartphones como ferramenta de aprendizagem e interação entre alunos e professores. Os estudos histológicos demandam ferramentas de visualização acurada de imagens, tanto quanto a descrição de seus conceitos. O presente trabalho objetivou a construção do aplicativo "Histologia Fácil", possibilitando ao interessado recursos de pesquisas e meios interativos de aprendizagem de fácil acesso. O aplicativo, disponível para dispositivos móveis, foi montado no formato de atlas histológico, com apresentação de imagens histológicas em três aumentos (4x, 10x e 40x), referentes a cada tecido dos sistemas orgânicos, com introdução e legenda descritiva para cada fotomicrografia. Foi utilizada como plataforma de desenvolvimento a "Fábrica de Aplicativos", que atende às necessidades de segurança, hospedagem, interatividade, acessibilidade e gratuidade. O Histologia Fácil foi desenvolvido em parceria com o Laboratório de Computação Aplicado as Ciências Agrárias e o Laboratório de Histologia Animal, ambos da Universidade Federal da Paraíba. A ferramenta está disponível para download gratuito nos formatos Android e iOS. Este aplicativo constitui-se uma alternativa auxiliar, motivadora e de fácil acesso no processo de ensinoaprendizagem da área de Histologia.
\end{abstract}

Palavras-chave: Ferramenta pedagógica; Interatividade; Tecnologia da informação.

\section{Histologia fácil: histological atlas for mobile devices}

\begin{abstract}
The evolution of the media and its use in all areas of teaching and research is undeniable. Today, phones have endless features that meet the varied demands of their users' daily lives. The academic routine incorporated smartphone technology as a tool for learning and interaction between students and teachers. Histological studies require accurate image visualization tools as well as the description of their concepts. The present work aimed at the construction of the "Histologia Fácil" application, enabling the interested researcher resources and interactive means of learning with easy access. The application, available for mobile devices, was assembled in the histological atlas format, presenting histological images in three magnifications $(4 \mathrm{x}, 10 \mathrm{x}$ and $40 \mathrm{x}$ ), referring to each tissue of the organic systems, with introduction and descriptive legend for each photomicrography. The "Fábrica de Aplicativos" was used as a development platform, which meets the needs of security, hosting, interactivity, accessibility and gratuity. The Histologia Fácil was developed in partnership with the Laboratório de Computação Aplicado as Ciências Agrárias and the Laboratório de Histologia Animal, both of the Universidade Federal da Paraíba. The tool is available for free download in Android and iOS formats. This application is an auxiliary, motivating and easily accessible alternative in the teaching-learning process in the area of Histology.
\end{abstract}

Key-words: Pedagogical tool; Interactivity; Information technology.

\footnotetext{
${ }^{1}$ Submetido em 11/02/2019 e aprovado em 11/12/2019;

${ }^{2}$ Departamento de Ciências Veterinárias, Universidade Federal da Paraíba, Areia, Paraíba, Brasil; e-mail: psicólogohelder@hotmail.com ORCID: 0000-0001-9265-8966;

${ }^{3}$ Programa de Pós-graduação em Ciência Animal, Universidade Federal da Paraíba, Areia, Paraíba, Brasil; E-mail: lucasrveter@gmail.com ORCID: 0000-0002-5875-8573; rromaoguerra@gmail.com - ORCID: 0000-0001-8226-8606;

${ }^{4}$ Departamento de Ciências Fundamentais e Sociais, Universidade Federal da Paraíba, Areia, Paraíba, Brasil; E-mail: marciamirandapb@gmail.com - ORCID: 0000-0001-8636-1349.
}

Agropecuária Técnica, Areia-PB, v. 40, n. 3-4, p. 88-94, 2019

https://doi.org/10.25066/agrotec.v40i3-4.44348 


\section{Introdução}

A histologia é o estudo das células e dos tecidos do corpo e de como essas estruturas se organizam para constituir os órgãos. Nos cursos de saúde, a disciplina de histologia é básica, tanto para compreensão do funcionamento dos sistemas dos seres vivos, quanto para a investigação das patologias e das disfunções celulares que essas causam. Para o diagnóstico histopatológico, o conhecimento histológico e todas as características de arranjo celular e morfologia são de fundamental importância (Junqueira e Carneiro, 2013). Portanto, o estudo da histologia demanda recursos de visualização de fotomicrografias dos tecidos histológicos, exigindo observação de todos os detalhes das estruturas analisadas. Além das imagens histológicas dos tecidos orgânicos, os conceitos das estruturas dos tecidos apresentados nas imagens, para melhor contribuição acadêmica e de pesquisa, devem ser descritos e explicados.

Comumente, o acesso aos conteúdos científicos desta ciência, de forma adequada, envolve uma série de limitações, uma vez que os compêndios, livros e atlas histológicos são volumosos e dispendiosos, e a visualização das lâminas histológicas demandam laboratórios adaptados e microscópios especializados em número suficiente que atenda à quantidade de estudantes interessados. Essas características limitam a logística e, diretamente, o processo de ensino e aprendizagem dos conteúdos da histologia, bem como carecem de modelos orgânicos de padrões de normalidade das estruturas histológicas acessíveis para pesquisas mais acuradas.

$\mathrm{Na}$ educação e na pesquisa científica, temos disponíveis novas tecnologias, acessíveis para a solução de problemas encontrados em recursos convencionais, bem como, para disseminação e facilitação no acesso ao conhecimento. A vida acadêmica também incorporou recursos tecnológicos para solucionar seus desafios. Hoje, os smartphones são utilizados pelos estudantes como ferramenta de aprendizagem e interação com a turma e professores. Agendamento de aulas, disponibilização de material de estudo e de pesquisas sobre os temas discutidos em sala de aula, já fazem parte das pesquisas dos estudantes, através dos smartphones.
De acordo com o censo de 2010, no Brasil, "entre os domicílios que acessaram à internet (inclusive os que utilizaram mais de uma forma de acesso), o percentual dos que o fizeram por microcomputador recuou de $88,4 \%$ para $76,6 \%$, enquanto a proporção dos domicílios que acessavam a internet por celular saltou de 53,6\% para 80,4\%" (IBGE, 2010), revelando que houve maior aquisição de aparelhos móveis e, com isso, o acesso à internet através dos mesmos.

Dentro do âmbito educacional, ao longo dos anos, diversas mudanças ocorreram em virtude da evolução das tecnologias da informação e comunicação (TIC's) e popularização da internet, possibilitando inserir, dentro e fora da sala de aula, inúmeros recursos, desde slides, quadros interativos, programas de TV educacionais, computadores pessoais, smarthpones e tablets, aplicativos interativos, etc.

Desse modo, ferramentas alternativas que supram as demandas de estudos e pesquisas da área de histologia, como alternativas para as limitações de acesso na pesquisa de imagens histológicas e facilidades de acesso e pesquisa em histologia, são necessárias e urgentes, para alcançar, democraticamente, um maior número de discentes, pesquisadores e usuários dessa área.

Assim, a criação de um espaço virtual e interativo, de fácil acesso e gratuito à comunidade científica e educacional, disponível, através de um banco de imagens completo dos tecidos animais em alta resolução, com descrições detalhadas para facilitar $o$ entendimento, bem a disponibilização de uma plataforma, através de um aplicativo móvel com perfil de interatividade para estudo, leitura de textos e visualização de imagens, de acesso gratuito à comunidade científica e educacional, fazem-se necessários, uma vez que possibilita ofertar, aos interessados sobre o tema, recursos de pesquisas e aprendizado flexíveis, superando as limitações supracitadas para o estudo e pesquisa da área.

O presente trabalho tem por objetivo descrever a criação e manutenção de um Atlas Histológico, disponível no formato de aplicativo para dispositivos móveis, utilizando recursos de plataforma de construção de aplicativo, gratuita, em língua portuguesa, segura e de fácil acesso 
aos interessados pelo tema, para facilitar o acesso e compartilhamento do conhecimento científico na área da Histologia.

\section{Material e Métodos}

Foi realizado um levantamento de necessidades junto a pesquisadores e estudantes nos trabalhos da área de histologia, objetivando auxiliar a consulta de imagens e de suas especificações. $\mathrm{O}$ processo metodológico utilizado consistiu de quatro fases, a saber:

1. Levantamento do laminário a ser construído;

2. Capacitação da equipe de trabalho para a construção do laminário, planejamento e construção do banco de dados e aplicativo;

3. Planejamento e construção do banco de dados;

4. Planejamento e construção do aplicativo móvel.

A primeira parte do trabalho foi desenvolvida através de um levantamento e análise do laminário existente no Laboratório de Histologia Animal da Universidade Federal da Paraíba (UFPB), para descrição detalhada e catalogação digital. Estes procedimentos serviram de coleta e armazenamento de dados para construção do banco de dados digital e do aplicativo móvel em foco, como sua base de conhecimento digital.

Para o desenvolvimento e execução dos produtos desse projeto, foram planejados e executados planos de capacitação com a equipe do projeto para investigação de ferramentas e/ou plataformas desenvolvedoras para aplicativos móveis, bem como para aquisição de habilidades de manuseio e desenvolvimento desses aplicativos.

A partir do laminário construído, foi desenvolvido o banco de dados com imagens e legendas dos cortes histológicos. Daí, iniciou-se as adequações do banco de dados para atender as demandas do aplicativo, havendo a necessidade de planejamento dos procedimentos que norteariam a utilização das informações, pertinentes ao banco de dados, pelo aplicativo. $\mathrm{O}$ banco de dados, construído a partir do laminário, está disponível digitalmente, em alta resolução e em 3 aumentos, para consulta e estudos acurados e detalhados por parte dos pesquisadores da área e demais interessados.
O aplicativo desenvolvido, chama-se Histologia Fácil, montado na forma de atlas histológico, com apresentação de imagens histológicas, referentes a cada órgão de cada sistema orgânico estudado. Ademais, apresenta uma breve introdução e legenda descritiva de cada imagem. As informações contidas são provenientes da confecção de lâminas histológicas de vários tecidos, com posterior digitalização de fotomicrografias e avaliação pela equipe responsável.

Após pesquisa de possíveis plataformas de desenvolvimento de aplicativos para dispositivos móveis, a plataforma Fabrica de Aplicativos foi utilizada para a construção do aplicativo estruturado como atlas histológico. Essa plataforma foi escolhida por possuir interface em idioma português, visual e, prioritariamente, desenvolvida no sistema Java, que se constitui em importante linguagem padrão para a construção e a manutenção de programas científicos. Ademais, ela atendeu às necessidades de segurança, hospedagem, interatividade, acessibilidade e gratuidade necessárias ao foco desse trabalho.

Para a presente pesquisa, não houve a necessidade de aprovação da Comissão de Ética Animal, haja vista que o material que foi utilizado, para a confecção das lâminas, já estava processado e disponibilizado à pesquisa, pelo Laboratório de Histologia da UFPB. O planejamento e desenvolvimento do aplicativo foram realizados no Laboratório de Computação Aplicado as Ciências Agrárias (LACACIA) da UFPB, utilizando sua infraestrutura computacional e didática.

A construção da ferramenta compreendeu as fases e etapas de desenvolvimento elencadas na Figura 1. Seguindo a definição dos requisitos pertinentes ao aplicativo, execução do designer de acordo com o esperado na interatividade e respeitando a arquitetura disponível pela plataforma; após a montagem de todos os sistemas estudados, foi disponibilizado o protótipo de acesso através link, para que os membros da equipe e colaboradores pudessem testar a sua versão Beta, anterior a versão completa e testada.

Após o desenvolvimento da versão inicial, representativa ao esboço, serão realizados sucessivos testes no protótipo inicial, que 
resultarão na reavaliação e otimização do aplicativo. Em sua versão final, o aplicativo será disponibilizado, nas devidas plataformas, para acesso gratuito e download nos Sistemas
Operacionais Android e iOS, bem como haverá a divulgação no próprio local de seu desenvolvimento, no Centro de Ciências Agrárias da UFPB.

Figura 1 Fases de desenvolvimento do Aplicativo "Histologia Fácil"

\begin{tabular}{|c|c|c|c|}
\hline Fase & Iteração & Descrição & Marco Associado \\
\hline Iniciação & Iniciação & Definição de requisitos do Aplicativo & $\begin{array}{l}\text { Especificação de requisitos } \\
\text { funcionais e adicionais }\end{array}$ \\
\hline Elaboração & Protótipo & $\begin{array}{l}\text { Análise e Design de Uso e } \\
\text { desenvolvimento do protótipo da } \\
\text { arquitetura }\end{array}$ & Protótipo de arquitetura \\
\hline Construção & Primeiro Release & $\begin{array}{c}\text { Implementação e teste dos Casos de uso } \\
\text { da fase anterior }\end{array}$ & Primeiro Release \\
\hline Transição & Release Final & $\begin{array}{l}\text { Testes finais e eventuais melhoramentos } \\
\text { e correção de defeitos. }\end{array}$ & Release Final \\
\hline
\end{tabular}

A arquitetura de utilização do aplicativo seguiu a regra dos três cliques (Three Click Rule), conhecida como regra do bom uso do designer, que, sucintamente, consiste da funcionalidade de uma estrutura em árvore, oferecendo o acesso através da interface, organizada da seguinte forma:

1. Sistema orgânico escolhido;

2. Órgão do sistema orgânico escolhido.

3. Acesso às imagens em cortes histológicos, em três dimensões, com o aumento (Zoom) de 4X, 10X e 40X, incluindo suas respectivas legendas de explicação.

Essa arquitetura está ilustrada na Figura 2.
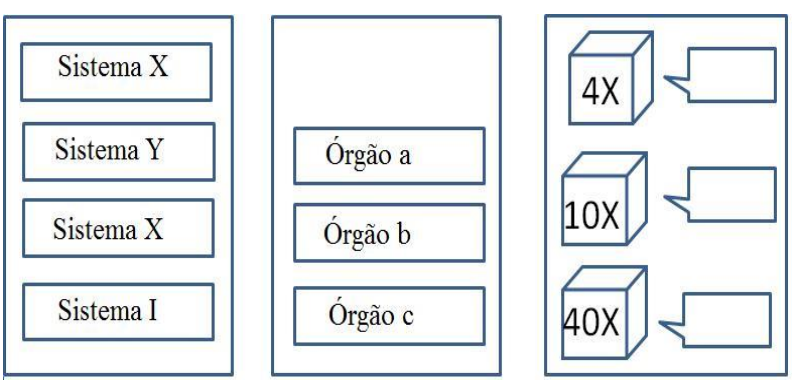

Figura 2 Representação do esquema em árvore pelo qual o aplicativo será construído.

\section{Resultados e Discussão}

A partir da escolha da plataforma, foram construídos o design gráfico do aplicativo, no sentido que atendesse à estrutura de Abertura - com suas opções de escolhas, menu interativo e modelo-cartão da microfotografia histológica e descrição de suas estruturas. Ao clicar no ícone do aplicativo na tela do celular, ilustrada na Figura 3, abrir-se-á a interface geral do aplicativo composta por uma caixa de diálogo interativa onde pode-se digitar o nome do órgão e/ou tecido escolhido e assim indo direto ao que se deseja consultar, ou pode-se acessar a partir de ícones específicos de cada sistema orgânico: sistema nervoso, respiratório, cardiovascular, urinário, digestório, endócrino, reprodutores e musculoesquelético.

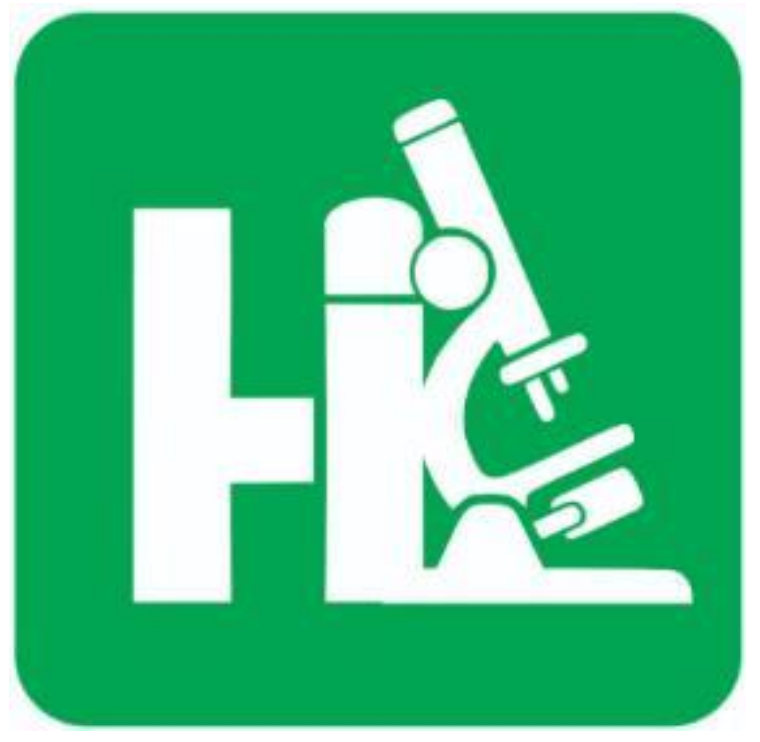

Figura 3 Ícone de apresentação do aplicativo. Representa o link para acesso ao aplicativo Histologia Fácil. 
Ao realizar a escolha em cada ícone do sistema interessado, conforme disponibilizado e

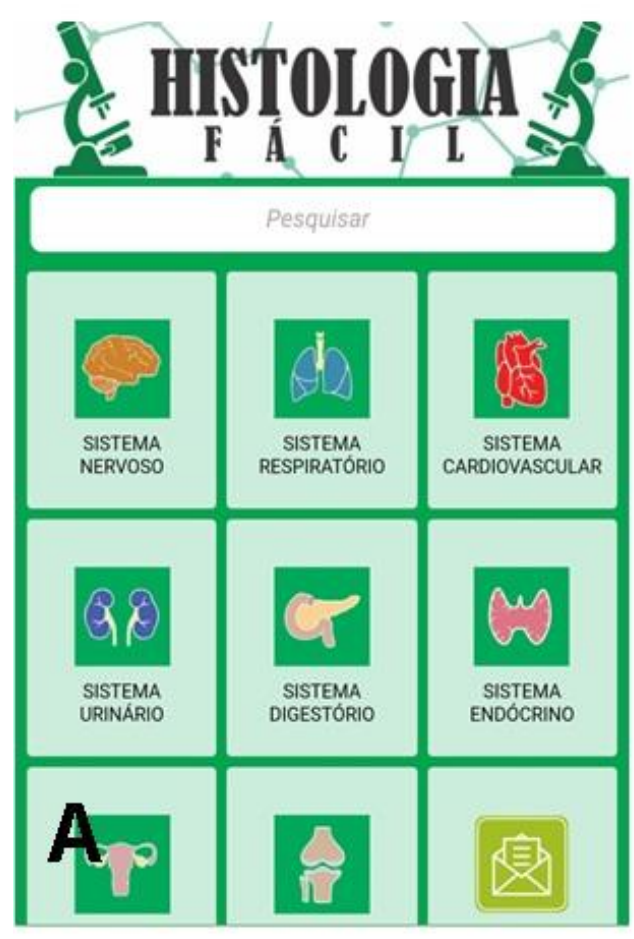

ilustrado na Figura 4, o usuário acessará imagens de cada órgão que deseja consultar.

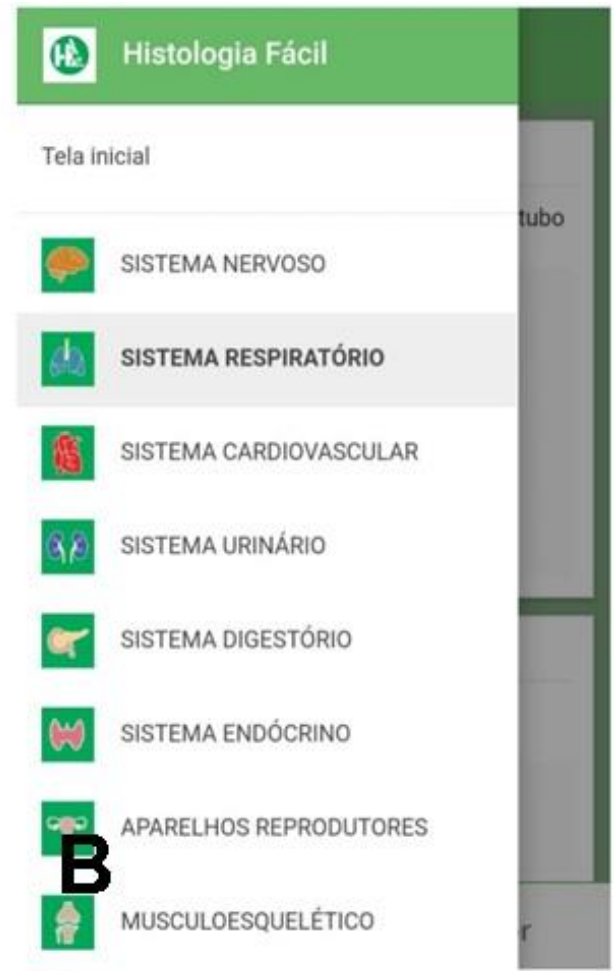

Figura 4 (A) Menu de acesso aos sistemas orgânicos, composto por: cabeçalho com o nome do aplicativo, barra de pesquisa e ícones para acesso aos tecidos. (B) Menu de acesso rápido aos tecidos.

Ao acessar o órgão de interesse, haverá um texto introdutório de cada tecido que será analisado, um texto que descreve todas as estruturas que compõem esse tecido e as referências das estruturas legendadas. Em forma de cascata, cada imagem possui cortes histológicos em 4x, 10x, 20x e 40x, cada uma com suas referências, explicações e descrições pormenorizadas em Modelo-cartão onde as imagens apresentam fotomicrografias de tecidos histológicos e descrição histológica dos tecidos em suas dimensões, como mostra a Figura 5.
Há, ainda, a possibilidade de acessar um menu rápido, semelhante a um atalho, onde o acesso se dá de forma direta, excelente para quem tem dúvidas específicas por legendas de cores específicas. Essa ferramenta será melhor utilizada a partir do momento que o usuário possuir mais familiaridade com o aplicativo, salientando que sua construção foi realizada, utilizando a padronização universal de acesso cascata, tornando seu aprendizado e utilização bastante simples e natural. 


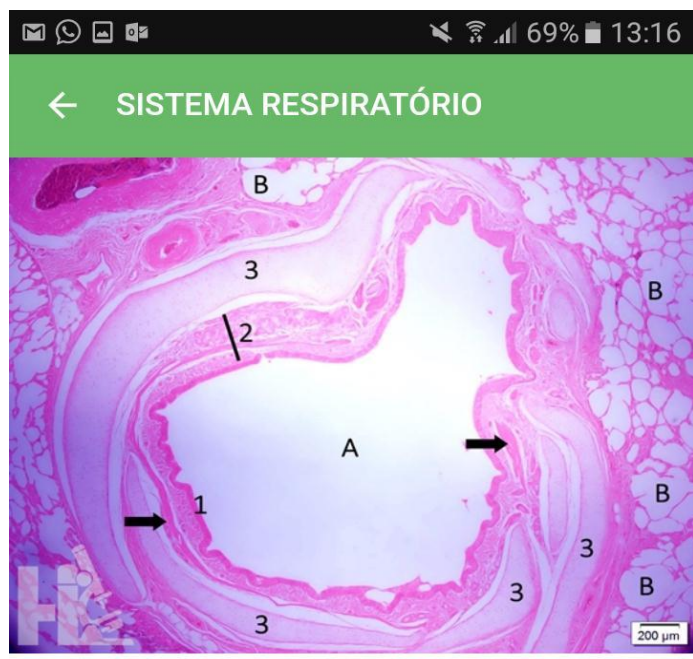

\section{Brônquios}

Os brônquios primários ou principais são constituídos da mesma maneira que a traqueia, mas tem menor diâmetro. Cada brônquio tem seu próprio tronco nervoso, vascular e linfático que se ramifica com cada divisão das vias aéreas. A cada subdivisão do brônquio, o diâmetro da via também vai diminuindo, e o epitélio respiratório também vai se tornando mais curto (baixo).

Nos brônquios observa-se dobras na mucosa

www.fabricadeaplicativos.com.br

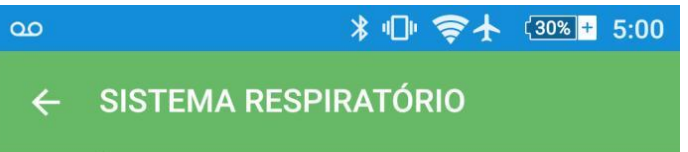

BRÔNQUIO 4X

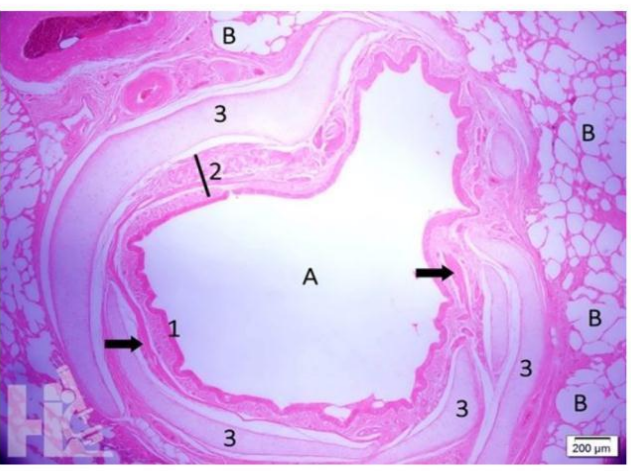

Fotomicrografia de brônquio (A) com epitélio prismático (1), lâmina própria (2) com aparecimento de músculo liso (setas) que promove o pregueamento do epitélio. Observa-se ao redor alvéolos (B) do parênquima pulmonar. Coloração hematoxilina-eosina.

www.fabricadeaplicativos.com.br $\triangle$

Figura 5 Modelo-cartão onde se apresenta a fotomicrografia de tecido histológico e a respectiva descrição histológica dos tecidos em seus diferentes aumentos (zoom).

\section{Conclusão}

A oferta de recursos de aprendizagem que utilizam o celular como ferramenta, hoje se apresenta como estratégia eficiente de acesso e interatividade motivadoras. Ter na palma da mão, a qualquer hora e em qualquer lugar, o material de consulta para esclarecimento de conhecimentos científicos trará grande impacto no modelo de aprendizagem na contemporaneidade.

O aplicativo Histologia Fácil traz conteúdo científico e imagens histológicas de qualidade, ofertando aos interessados pelo tema, conteúdo de qualidade, de fácil e rápida consulta. Podendo ser utilizado como ferramenta para comparações de estudos histológicos, auxiliar em aulas conceituais e de monitorias das disciplinas nas áreas Biológicas e da Saúde, sem as limitações estruturais e quantitativas encontradas nos laboratórios de estudos histológicos comumente utilizados.

\section{Referências}

Ally, M.; Grimus, M.; Ebner, M. Preparing teachers for a mobile world, to improve access to education. Prospects, v. 44, n. p. 43-49, 2014. https://doi.org/10.1007/s11125-014-9293-2

Anderson, J.; Rainie, L. The Future of Apps and Web. Ed. MIT. 2012. Disponível em: < http://www.pewinternet.org/2012/03/23/the-future-ofapps-and-web/ > Acesso em: 23 dez 2018.

Barbosa, S. E. S.; Carmo, L. A. do; Medeiros, R. L. S. F. M; Cabral, S. A. A. O.; Aquino, R. S. $\mathrm{P}$. de. $\mathrm{O}$ processo unificado integrado ao desenvolvimento Web. Revista Engenharia de Software. v. 1, n. 1, p. 28-77, 2016. https://profandreluisbelini.files. wordpress.com/2016/02/r evista-engenharia-de-software-ano-1-1c2baedic3a7c3a3o.pdf

Lopes, R. E. M.; Alves, M. N. T. Impacto na Rotina Acadêmica pela Utilização de Novas Tecnologias por Estudantes de Medicina do Semiárido Paraibano. Id online Revista 
Multidisciplinar e de Psicologia, v. 12, n. 39, p. 695-712, 2018. https://idonline.emnuvens.com.br/id/article/download/102 $2 / 1460$

Batista, S. C. F.; Barcelos, G. T. Análise do uso do celular no contexto educacional. Novas Tecnologias na Educação, v. 11, n. 1, p. 2-10, 2013. https://doi.org/10.22456/1679-1916.41696

Guariba Filho, F.M. Desenvolvimento de um Game para Android O.S. 2012. 54f. Monografia (Bacharelado) - Ciência da Computação, Faculdade de Ciências, Unesp Bauru, Bauru-SP.

Handal, B.; Ritter, R.; Marcovitz. Implementing Large Scale Mobile Learning School Programs. EdMedia, Tampere, Finlandia. v. 1., 2014. p. 2326.

IBGE. Censo Demográfico 2010: Características gerais da população, religião e pessoas com deficiência. Instituto Brasileiro de Geografia e Estatística - IBGE, Rio de Janeiro, 2010. 215p. Disponível em: < https://biblioteca.ibge.gov.br/visualizacao/Perio dicos/94/cd_2010_religiao_deficiencia.pdf > Acesso em: 13 mar 2018.
Junqueira, L. C.; Carneiro, J. Histologia básica. $12^{\mathrm{a}}$ ed. Rio de Janeiro: Editora Guanabara Koogan, 2013. 538p.

Melo, R. S.; Carvalho, M.J.S. Aplicativos Educacionais Livres para Mobile Learning. XI EVIDOSOL e VIII CILTEC - Online. 2014. Disponível em: < http://evidosol.textolivre.org/site/ Acesso em: 13 mar 2018.

Sacool, A. I. C. Z.; Schlemmer, E.; Barbosa, J. L. V; Reinhard, N; Sarmento, C. M-Learning ou Aprendizagem com mobilidade: Um estudo exploratório sobre sua utilização no Brasil. XXXI Encontro da ANPAD. p.16. 2017. Disponível em: < http://www.anpad.org.br/admin/pdf/ADI-B706.pdf > Acesso em: 22 set 2018.

Nielsen, J.; Budiu, R. Mobile Usability. Berkeley: New Riders, 2013. 204p.

Power, J. L. Mobile apps for librarians. Journal of Access Services, v. 10, n. 2, p. 138-143. 2013. https://doi.org/10.1080/15367967.2013.767690

Zeldman, J. Taking Your Talent to the Web: making the transition from graphic design to web design. New Riders Ed. 2001. 448p. 